\title{
Ethical issues around access to over-the-counter medicines in South Africa
}

\author{
N Padayachee, ${ }^{1}$ BSc, BPharm, MPharm; A D Rothberg, ${ }^{1}$ MB BCh, PhD; J Gardner, ${ }^{2}$ MMed, PhD; I Truter, ${ }^{3}$ MCom, DCom, BPharm, MSc, PhD; \\ N Butkow, ${ }^{1}$ BSC, MSc, PhD \\ 'Department of Pharmacy and Pharmacology, School of Therapeutic Sciences, Faculty of Health Sciences, University of the Witwatersrand, \\ Johannesburg, South Africa \\ ${ }^{2}$ Department of Bioethics, School of Clinical Medicine, Faculty of Health Sciences, University of the Witwatersrand, Johannesburg, South Africa \\ ${ }^{3}$ Department of Pharmacy, Faculty of Health Sciences, Nelson Mandela University, Port Elizabeth, South Africa
}

\section{Corresponding author: N Padayachee (Neelaveni.padayachee@wits.ac.za)}

\begin{abstract}
South Africa is engaged in a heated debate around how to achieve universal healthcare (UHC) that will be accessible to all, affordable for the country and of high quality. Essentially, this discourse frames UHC as a right, yet there is strong evidence that certainly in the privately funded sector, healthcare functions as a commodity within a failing market system. Research has shown these failures to affect the highest cost elements of hospital, specialist and chronic disease care. In this review, we show that commoditisation also affects the primary healthcare market, specifically in the area of over-the-counter (OTC) medicines. The segment represents a multibillion-rand contribution to the economy, with stakeholders - ranging from government, pharmaceutical manufacturers and pharmacists to medical schemes and their members - driving the costs of OTC medicines up rather than down.
\end{abstract}

S Afr J Bioethics Law 2019;12(2):71-75. https://doi.org/10.7196/SAJBL.2019.v12i2.676

Some years back, a cartoon appeared showing a swarthy Mafia caricature in a suit, seated behind an executive desk in a plush office. The caption: 'I used to deal illicit drugs until I realised there was more money selling ethical medicines.' This cynical but prescient comment on the costs of one of the most important elements of healthcare is particularly disturbing because it relates to cost and price manipulation of ethical medicines, which, typically, are regulated, i.e. subject to national drug registration and/or scheduling systems; require a doctor's prescription; and are restricted in terms of access to the public. If price and cost elasticity exist for 'ethical' products, what is the situation for over-the-counter (OTC) medicines, which are not regulated to the same extent, are directly accessed by consumers, are enthusiastically produced by numerous competing manufacturers and are aggressively sold by pharmacies?

In the South African (SA) public sector (covering healthcare for $\sim 85 \%$ of the population), OTC medicines are managed by the tender system and the Essential Medicines List (EML). ${ }^{[1]}$ These two initiatives enable the state to limit the number of available products, and fix the prices of OTC medicines for the population that it serves at primary healthcare $(\mathrm{PHC})$ level. The EML predominantly includes single-ingredient products, so recipients have limited access to numerous higher-priced multi-ingredient OTC medicines (which in general do not have a sound evidence base ${ }^{[2]}$ ). In the private sector, there are several stakeholders in the OTC value chain (Fig. 1), many with conflicts of interest and all exposed to perverse incentives that could influence their ability or willingness to achieve access to affordable, high-quality OTC medicines, as a goal. Herein lies an important assumption: viz., that access to affordable high-quality medicines is indeed the goal.
This assumption also introduces the key question of whether healthcare is a commodity or a right. ${ }^{[3]}$

The commodity argument proposes that the marketplace governs demand, supply and the cost of healthcare while consumers/patients rationally make choices according to needs. Society benefits as costs decline through market competition, and quality improves through competitive advantage. The argument that healthcare is a right posits that healthcare is a need and not a choice, and that profit motives undermine the doctor-patient relationship. It argues that government should regulate standards of care that could be vulnerable to compromise (e.g. if insurers try to minimise costs), and should act to reduce the information asymmetry that precludes patients from behaving as informed consumers. ${ }^{[3]}$ The current debate around National Health Insurance $(\mathrm{NHI})^{[4]}$ in SA is firmly based on access to healthcare being a right, but certainly within the private sector, the preliminary findings of the Health Market Inquiry, ${ }^{[5]}$ which focused on private hospitals, specialists and medical schemes, indicate that healthcare is commoditised. If healthcare is performing as a commodity at the top end of the cost spectrum, what is the situation for OTC medicines in the PHC domain? Economists would probably argue that if OTC medicines are a commodity, then stakeholders, from manufacturers, distributors, medical schemes and healthcare providers all the way through to consumers, would endeavour to drive costs down. Our previous research ${ }^{[6]}$ has shown that this is not the case: parties on the supply side appear to prioritise profit, while consumers on the demand side show little interest in quality or value. These behaviours call into question the ethical and moral values of stakeholders. 


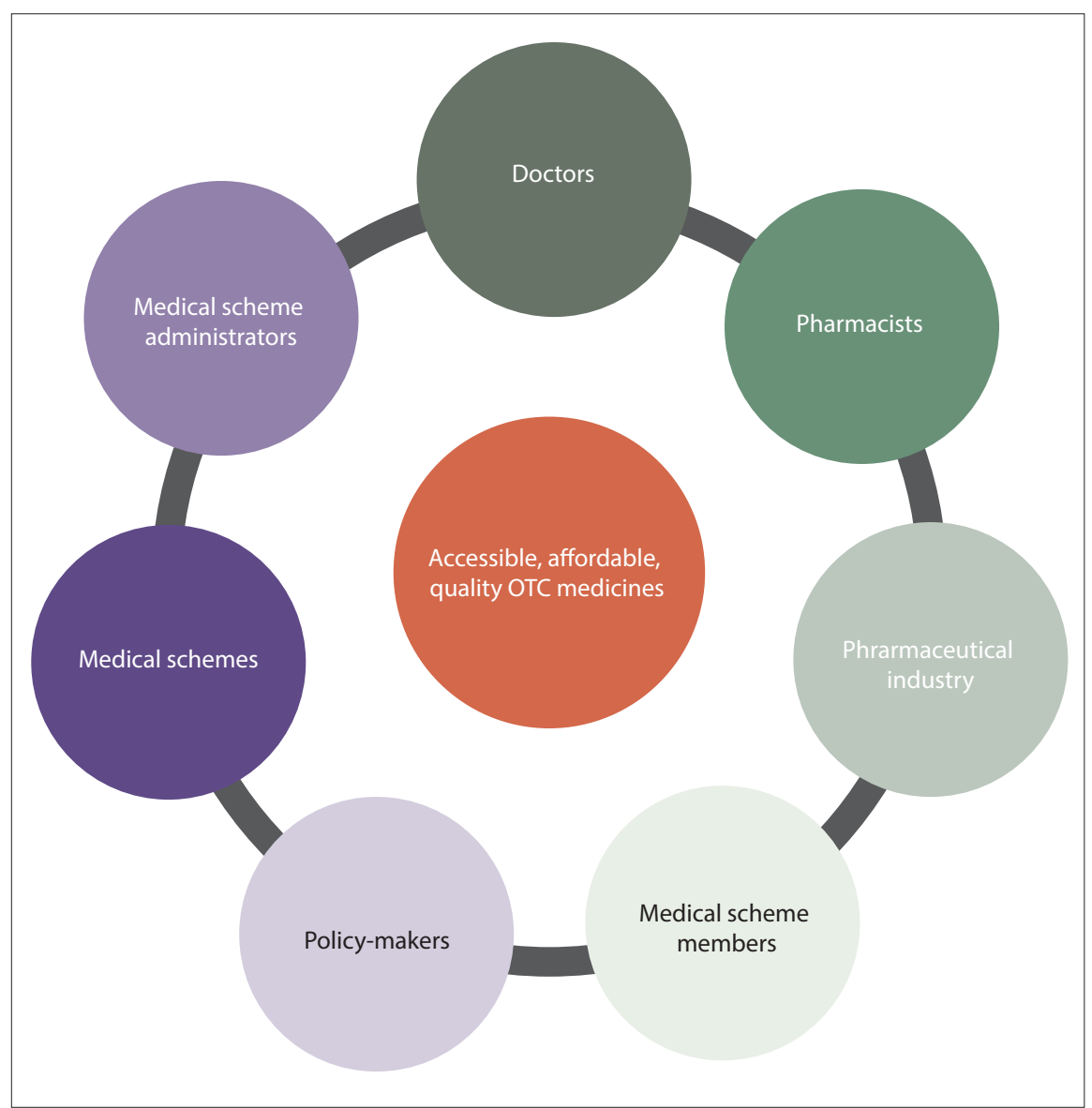

Fig. 1. Stakeholders involved in the access, affordability and quality of over-the-counter (OTC) medicines supply and demand chains in the private sector.

We have previously studied utilisation of the OTC medicine benefit in two medical scheme plans, one offering a set of comprehensive benefits at the top end of the range, the other offering more-restricted access to benefits. ${ }^{[6]}$ In the present article, the research findings are applied to the various stakeholders in the OTC supply and demand chains, and are discussed in terms of stakeholder behaviour as it relates to access to medicines as well as their quality and costs.

\section{Methodology}

The empirical data referred to in this review were extracted from a database of medical schemes' OTC medicines claims, and analysed for a PhD submission. Publicly available sources relevant to the privately funded healthcare sector were also reviewed, as were guidelines from professional bodies and relevant Acts and regulations pertaining to the costs and quality of and access to OTC medicines.

\section{Pharmacists and pharmacies}

Our research has shown that medical scheme expenditure on OTC medicines in two high-volume disease categories (covering minor respiratory ailments, i.e. coughs and colds, and ailments requiring analgesia/ mild sedation, respectively) appears to be higher when pharmacists recommend or dispense medicines than when doctors prescribe or dispense for the same set of ailments. Pharmacists have added leeway to recommend more expensive products and products containing multiple ingredients, thereby adding to the cost without necessarily adding much in the way of therapeutic value. ${ }^{[2,7]}$ The costs are also higher if the customer belongs to a medical scheme with more generous benefits. ${ }^{[6]}$ Also shown in our research was that average cost differentials were very different for two multi-ingredient analgesic products, both containing paracetamol, codeine, caffeine and doxylamine, where product $A$ is the original and $B$ the generic version (Table 1 ).
In these examples, 'cost' refers to the amount claimed by the service provider (i.e. the price), and not the amount actually paid by the medical schemes.

Perhaps the starting point for understanding the factors that drive or direct the behaviour of pharmacists is an examination of professional guidelines. According to the SA Pharmacy Council's applicable code of conduct, 'the pharmacist's goal in the provision of medicine therapy should be to achieve appropriate therapeutic outcomes that contribute towards patient health and quality of life. The attitudes, behaviours, commitments, concerns, ethics, functions, knowledge, responsibilities and skills of the pharmacist should therefore be focused on primarily benefiting the patient and the public as a whole. ${ }^{[8]}$ While noble in intent, the code of conduct grants latitude in the provision of OTC medicines, and much is left to the individual pharmacist. The 'Good pharmacy practice' (GPP) guidance document $^{[9]}$ provides a set of minimum standards for practising pharmacists in SA. Within the GPP, the 'Pharmacist-assisted therapy (OTC medicines) minimum standard' states that medicines must be selected based on quality, efficacy and safety. For the pharmacist, there is often a conflict between applying the guidelines and his or her autonomy and relative freedom to provide advice and guidance. ${ }^{[10]}$ In terms of the cost of OTC medicines, the pharmacist is frequently under pressure to generate profits, whether (s)he is the owner of the pharmacy or an employee. This can be done by making a particular product more visible in the pharmacy, or promoting its use, particularly to medical scheme beneficiaries whose benefit plans cover the cost Furthermore, many pharmacies are owned by large corporations whose goal is to deliver profits to shareholders. These factors may influence the ethical and professional judgement of pharmacists. ${ }^{[1]}$

From the above, it is clear that guidelines and codes of conduct are not prescriptive, and there is some reliance on the conscience of the pharmacist. From the perspective of legislation, a number of Acts and their regulations have the potential to affect provision of OTC medicines (Table 2 ), but again the legislation is relatively weak. Consequently, pharmacists may generally be in compliance, but as shown in Table 1, 
Table 1. Average cost in ZAR of two versions of a multi-ingredient OTC product according to high- $v$. low-benefit medical scheme plan and pharmacist $\mathbf{v}$. doctor as provider

\begin{tabular}{|c|c|c|c|c|}
\hline \multirow[b]{2}{*}{ Product } & \multicolumn{2}{|c|}{ High-benefit plan } & \multicolumn{2}{|c|}{ Low-benefit plan } \\
\hline & Recommended by pharmacist & Prescribed by doctor & Recommended by pharmacist & Prescribed by doctor \\
\hline A & 110.08 & 90.81 & 71.50 & $-*$ \\
\hline B & 66.86 & 46.24 & 49.74 & $\mathrm{R} 16.47$ \\
\hline
\end{tabular}

Table 2. Regulatory organisations, policies and legislation, and impact on OTC medicines

\begin{tabular}{|c|c|c|}
\hline Regulatory body & Policy/regulation/legislation (MRSA) ${ }^{[12]}$ & Impact/effect \\
\hline NDoH and SAHPRA & Guidelines, section $22 \mathrm{~A}$ and $37 \mathrm{~A}$ & $\begin{array}{l}\text { Guidelines emphasise importance of proper counselling on and } \\
\text { recording of OTC and other medicines, e.g. access to codeine } \\
\text { is limited to } 10 \mathrm{mg} \text { per tablet/capsule. However, more than the } \\
\text { stipulated quantity is possible if recording practices are poor or } \\
\text { one member of a family accesses medicines on another's card. }\end{array}$ \\
\hline $\mathrm{NDoH}$ & Single exit price, section $22(\mathrm{G} 3)$ & $\begin{array}{l}\text { Promotes transparent pricing, i.e. product sold to all pharmacies } \\
\text { at the same price (but OTC costs may nevertheless vary for same } \\
\text { product, influenced by variable application of dispensing and } \\
\text { logistics fee). }\end{array}$ \\
\hline $\mathrm{NDoH}$ & Dispensing fee, section 22(G1b) & $\begin{array}{l}\text { Pharmacists and dispensing doctors charge a fee over and above } \\
\text { the cost of the medicine (while subject to maximum amounts, } \\
\text { dispensing of more expensive medicines results in a higher. } \\
\text { dispensing fee, as fees are proportional to cost of product) }\end{array}$ \\
\hline $\mathrm{NDoH}$ & Dispensed quantity, section $22(\mathrm{M})$ & $\begin{array}{l}\text { Quantity of medicines dispensed should not exceed or be less } \\
\text { than } 25 \% \text { of the amount on prescription, but pharmacists appea } \\
\text { to be going beyond the specified limits }\end{array}$ \\
\hline $\mathrm{NDoH}$ & Generic substitution, section 22(F) & $\begin{array}{l}\text { With patient approval, medicines dispensed by pharmacist or } \\
\text { dispensing doctor are subject to generic substitution, unless } \\
\text { 'no substitution' is stated by the prescribing doctor. Similarly } \\
\text { constituted generics may vary in price. }\end{array}$ \\
\hline
\end{tabular}

OTC $=$ over-the-counter; MRSA = Medicines and Related Substances Act No. 101 of 1965, as amended in Government Gazette May 2017; NDoH = National Department of Health; SAHPRA = South African Health Products Regulatory Authority.

there are significant opportunities for price manipulation and income generation. Furthermore, as shown in a recently aired investigative report $^{[13]}$ into the ease with which codeine abusers acquire quantities of codeine-containing cough mixtures, compliance with legislation may be less than ideal, and regulatory oversight may be weak. In the context of healthcare as commodity v. right, the evidence suggests that OTC medicines are squarely in the commodity court, but if the goal of commoditisation is a free market in which forces endeavour to drive costs down, then the market is failing, and not providing the most appropriate medicines of the highest quality at the lowest cost.

\section{Medical schemes/administration companies}

According to the Medical Schemes Act No. 131 of 1998, ${ }^{[14]}$ managed healthcare strategies may be employed by medical schemes. Managed care itself is defined as 'clinical and financial risk assessment and management of healthcare, with a view to facilitating appropriateness and cost-effectiveness of relevant health services within the constraints of what is affordable, through the use of rules-based and clinical management-based programmes.'[15] This aligns with the three pillars of managed healthcare, viz. control of cost, quality and access. However, little is being done by medical schemes or their administrators to curb the costs and/or maintain the quality of OTC medicines. Rather, the focus of the schemes and their administrators is the management of prescribed minimum benefits (PMBs), a legislated set of benefits for specified conditions that must be accessible to all medical scheme beneficiaries. ${ }^{[13]}$ Primary healthcare is barely covered within the list of PMBs, and if an individual has PHC cover as a listed benefit, it is either only partially funded out of the risk pool or funded out of a 'savings' pool that is left to the beneficiary to manage. This is an unfortunate situation, since medical schemes and their administrators are in possession of substantial amounts of data that could be utilised to enhance health. In this regard, medical scheme beneficiaries could be informed that a higher price for one OTC product does not equate to better quality than found in another lower-priced product with identical ingredients. Education could extend to the actions of the various ingredients; for example, the addiction risks of prolonged ingestion of codeine. ${ }^{[16]}$ Our research has shown that codeine-based analgesic OTC medicines are widely accessed, ${ }^{[17]}$ and when used to treat minor ailments may lead to addiction, or they may simply be abused by individuals for recreational purposes. ${ }^{[6]}$ Furthermore, because medical schemes have data at the level of an individual beneficiary, they have the potential to monitor not only what is being used for treatment of minor ailments, but also the background against which there may be repeated use. For example, a frequent user of cough medicines 
who has a history of multiple visits to a doctor for wheezing could be identified by the scheme's administrator, and encouraged to be assessed for asthma and possible enrolment into a diseasemanagement programme.

Beyond education on the contents and costs of OTC medicines, medical schemes and administrators could further influence expenditure on OTC medicines by applying system-driven 'filters' such as a maximum medical aid price (MMAP) ${ }^{[18]}$ or a reference price list $(\mathrm{RPL})^{[19]}$ that would only permit payment for approved medicines on an authorised cost-per-combination basis. Engaging with doctors and pharmacies on a contractual basis also has the potential to manage the prescribing and dispensing of OTC medicines. ${ }^{[20]}$ There is also a role for the Council for Medical Schemes (CMS), the regulatory body responsible for oversight of medical schemes and the protection of their members. The CMS prides itself on the production of educational and informative material in electronic and hard-copy format, but the majority of its efforts are directed towards the PMBs, and are not related to PHC. ${ }^{[2]]}$ Overall, there appears to be little enthusiasm within the medical schemes environment for value-additive interrogation of data, or for spending money in order to save money.

\section{Pharmaceutical manufacturers and distributors}

Pharmaceutical manufacturers have a powerful influence on the sale of OTC medicines, as they are able to set the prices and compete with others based on branding, packaging and stakeholder loyalty. Legislation has been promulgated to provide a base cost for various products and facilitate the determination of dispensing fees for each product. ${ }^{[12]}$ However, while such single-exit-price legislation requires notification of the price of a product, it is silent on how a particular price is derived. Consequently, products of similar composition may have vastly different exit prices. This can be seen in Table 1, where for product $B$, there can be a four-fold difference between the average cost as submitted to the medical scheme by a pharmacist, and when prescribed by a doctor. In addition, legislation covering dispensing fees allows pharmacies the latitude to promote more expensive OTC products and in turn to generate higher dispensing fees (Table 2). Vertical integration may also be an issue, e.g. where a holding company has various businesses that individually manufacture OTC medicines, distribute medicines to patients or provide management systems that enable pharmacies to maximise profit. Medical scheme administration companies may be part of the vertically integrated package, opening the door to particular product(s) manufactured by a sister company being included in a medical scheme's list of recommended medicines. ${ }^{[5]}$ The multi-year $\mathrm{HMl}$ exercise into cost drivers within the medical schemes administration and private hospital environments delved into the complex interactions between stakeholders, ultimately concluding that there are indeed issues that are resulting in market failure and rampant escalations in costs. ${ }^{[5]}$ It is clear that similar issues affect the OTC market.

\section{Medical scheme members/beneficiaries}

Towards the end of each year, the medical schemes send beneficiaries the CMS-approved amendments to the following year's benefits and contributions. ${ }^{[22]}$ This facilitates a review of the appropriateness of benefits provided and, because contributions typically increase at a rate above general inflation, encourages beneficiaries to carefully consider factors such as affordability, and/or the need to change to a lower- or higher-cost benefit plan. In general, little attention is directed towards the OTC benefit, which ultimately is a 'nice-to-have' benefit not covered by the risk pool, and in effect is directly funded by the beneficiary, often with a co-payment. In the absence of consumer awareness, and a common belief that medical schemes profit from unutilised benefits, our research indicates that users of the OTC benefit pay little attention to the cost or appropriateness of OTC medicines. There appears to be a willingness to exhaust the benefit rather than extend its value by accessing equivalent but lower-cost products.

\section{Policy-makers}

Table 2 shows how government and various related entities have crafted policy, guidelines and legislation designed to regulate acquisition of OTC medicines by members of the public. However, as shown in the comment column, and very clearly shown in the recently televised investigative report into the ease of access to codeine-containing cough mixtures, ${ }^{[13]}$ these efforts to control cost, quality and access leave much to be desired.

The determination of government to implement UHC in SA is closely tied to the view that privately funded care via medical schemes is grossly discriminatory, exploitative, inefficient, unaffordable and unsustainable. The extent to which $\mathrm{NHI}$ will reduce the number of medical schemes and/or privately insured citizens is debatable, but it is likely that whatever the final offering in a medical scheme benefit package, access to OTC medicines will not be curtailed. For patients accessing public sector PHC facilities, the EML or a derivative/derivatives thereof would continue to control access to and cost and quality of OTC medicines. One may therefore speculate that government would have little interest in redrafting OTC-related legislation in order to influence utilisation in a (dwindling) privately funded sector of the population. On the other hand, there is support for the notion that government intervention would benefit a wider population: a recent corporate report gave the value of the annual OTC market in SA as ZAR10.2 billion. ${ }^{[23]}$ Extrapolation of our research data suggests that the privately funded element is only around ZAR3.4 billion (33\%) of that figure. The significant balance of R6.8bn thus represents out-of-pocket expenditure on OTC medicines by the general public, who would likely benefit from policy interventions.

\section{Doctors}

On the basis of the research conducted, doctors appeared to be the only stakeholders who impact positively on the cost of OTC medicines, by prescribing lower-priced products and promoting the use of generics. This is reassuring news for this often-maligned category of private healthcare providers. Within the 'doctor' category were both dispensing and non-dispensing doctors. The latter only prescribe for subsequent dispensing via a pharmacy, while the former have a licence to buy, prescribe and dispense medicines from within their practice. Of note here is that dispensing doctors, who could potentially benefit by prescribing more expensive OTC medicines, and their associated higher dispensing fees, ${ }^{[24]}$ appear to be the group prescribing most cost-efficiently (Table 3 ). Our research also showed that in general, there was excellent prescribing of generic products by doctors, and doctors tended to select cheaper generics than pharmacists. ${ }^{[6]} \mathrm{A}$ good example is reflected in Table 1, where it is shown that doctors treating patients in a low-benefit plan rarely 
Table 3. Average cost in ZAR of multi-ingredient OTC product B (generic) according to high- v. low-benefit medical scheme plan and dispensing v. non-dispensing doctor

\begin{tabular}{|c|c|c|c|c|}
\hline \multirow[b]{2}{*}{ Product } & \multicolumn{2}{|c|}{ High-benefit plan } & \multicolumn{2}{|c|}{ Low-benefit plan } \\
\hline & $\begin{array}{l}\text { Prescribed by } \\
\text { dispensing doctor }\end{array}$ & $\begin{array}{l}\text { Prescribed by non- } \\
\text { dispensing doctor }\end{array}$ & $\begin{array}{l}\text { Prescribed by } \\
\text { dispensing doctor }\end{array}$ & $\begin{array}{l}\text { Prescribed by non- } \\
\text { dispensing doctor }\end{array}$ \\
\hline B & 28.08 & 60.03 & 17.37 & 37.04 \\
\hline
\end{tabular}

prescribe the original (product A), and use the far less expensive, chemically equivalent generic.

\section{Conclusion}

The moral and ethical issues around OTC medicines involve a number of stakeholders who share the responsibility of providing medicines that are accessible, affordable and of good quality. In practice, the majority of stakeholders disappoint. Pharmacists favour more expensive OTC medicines over cheaper generics, medical schemes show little interest in managing these medicines from a cost and therapeutic perspective, beneficiaries lack interest in quality or cost, pharmaceutical companies bask in weak legislation and government apparently lacks the will to engage meaningfully on the topic.

The HMI was an initiative of the Competition Commission. ${ }^{[5]}$ Established in 2015 with input from local and international experts, its mission was to gain insight into the drivers of unsustainable increases in the costs of private healthcare in SA. The focus was on medical schemes, administrators, private hospitals and medical and surgical specialists. Interim findings published in 2018 drew attention to uninformed and disempowered consumers, a lack of value-based purchasing and little interest among medical schemes and administrators in reducing supplier-induced demand. The conclusion was that serious market failure exists in this environment. ${ }^{[5]}$ The results of our studies into access to and provision of OTC medicines are indicative of similar market failure in this area, ${ }^{[6]}$ and show that commoditisation ${ }^{[3]}$ also extends to the lower end of privately funded healthcare. Government intends to reverse this through $\mathrm{NHI}$, which aims to ensure that access to affordable quality healthcare is a right. Perhaps conflicting with this intention is the ruling party's recently announced 2019 election manifesto, which identifies the manufacture of pharmaceuticals as an opportunity for growth and economic empowerment for historically disadvantaged and disempowered South Africans. ${ }^{[25]}$

\section{Acknowledgements. None.}

Author contributions. NP conceptualised and provided the draft, ADR conceptualised and contributed to the final version, JG provided ethical guidance and NB and IT contributed to the final version.

Funding. None.

\section{Conflicts of interest. None.}

1. National Department of Health, South Africa. Standard Treatment Guidelines and Essential Medicines List. Pretoria: NDoH, 2015. http://www.health.gov.za/index. $\mathrm{php} / \mathrm{standard-treatment-guidelines-and-essential-medicines-list} \mathrm{(accessed} 4$ December 2018).

2. Murnion BP. Combination analgesics in adults. Austral Prescriber 2010;33(4):113-115.

3. Aggarwal NK, Rowe M, Sernyak MA. Is healthcare a right or a commodity? Implementing mental health reform in a recession. Psychiatr Serv 2010;61(11):11441145. https://doi.org/10.18773/austprescr.2010.056

4. National Department of Health, South Africa. National Health Insurance. Pretoria: NDoH, 2016. https://www.gov.za/sites/default/files/gcis_document/201908/ national-health-insurance-bill-b-11-2019.pdf (accessed 4 November 2019)
5. Health Market Inquiry, Provisional Findings and Recommendations. 2018. http:// www.compcom.co.za/wp-content/uploads/2018/07/Health-Market-Inquiry-1. pdf (accessed 10 January 2019).

6. Padayachee N, Rothberg AD, Truter I, Butkow N. Utilization of over-the-counter analgesics in two private medical insurance schemes in South Africa. Drug Healthc Patient Saf 2019;11:37.

7. Benson A, Cribb A, Barber N. Understanding pharmacists' values: A qualitative study of ideals and dilemmas in UK pharmacy practice. Soc Sci Med 2009;68(12):2223-2230. https://doi.org/10.1016/j.socscimed.2009.03.012

8. South African Pharmacy Council. BN 108 of 24 October 2008: Rules relating to Code of Conduct (Government Gazette No. 31534). Pretoria: SAPC, 2008. https:// www.mm3admin.co.za/documents/docmanager/3C53E82B-24F2-49E1-B9975A35803BE10A/00133607.pdf (accessed 2 February 2019).

9. South African Pharmacy Council. Good pharmacy practice. Pretoria: SAPC, 2010. http://apps.who.int/medicinedocs/documents/s19633en/s19633en.pdf (accessed 15 January 2019).

10. Rodríguez JV, Juričić Ž. Perceptions and attitudes of community pharmacists toward professional ethics and ethical dilemmas in the workplace. Res Soc Adm Pharm 2018;14(5):441-450. https://doi.org/10.1016/j.sapharm.2017.05.010

11. Wingfield J, Bissell P, Anderson C. The scope of pharmacy ethics - an evaluation of the international research literature, 1990 - 2002. Soc Sci Med 2004;58(12):23832396. https://doi.org/10.1016/j.socscimed.2003.09.003

12. South Africa. Medicines and Related Substance Act No. 101 of 1965, as amended in Government Gazette May 2017. https://www.sahpra.org.za/documents/abdb Obc7MedicinesandRelatedSubstancesAct101 of1965,asatMay2017.pdf (accessed 4 November 2019).

13. Carte Blanche Investigation. Codeine addiction: Signs and symptoms. M-net, DSTV, 11 November 2018. https://m-net.dstv.com/show/carte-blanche/news/ codeine-addictions-signs-and-symptoms-carte-blanche/news (accessed 10 January 2019).

14. South Africa. Medical Schemes Act No. 131 of 1998. https://www.medicalschemes, com/files/Acts\%20and\%20Regulations/MSACT19July2004.pdf. (accessed 15 February 2019).

15. Council for Medical Schemes. Managed health care policy document. Pretoria: CMS, 2003. http://www.medicalschemes.com/files/Guidelines\%20and\%20 Manuals/Managedhealthcare_Policy_doc_2003.pdf (accessed 4 November 2019).

16. Ricardo Buenaventura M, Rajive Adlaka M, Nalini Sehgal M. Opioid complications and side effects. Pain Physician 2008;11:S105-S120.

17. Foley M, Harris R, Rich $E$, et al. The availability of over-the-counter codeine medicines across the European Union. Public Health 2015;129(11):1465-1470. https://doi.org/10.1016/j.puhe.2015.06.014

18. Boyce D, Bartlett G. The maximum medical aid price programme: A review of the concept and of its ability to reduce expenditure on medicines. S Afr Med J 1990;78(8):147-151.

19. Rothberg, AD, Blignault, J, Serfontein CB, Valodia B, Eekhout S, Pels LM. Experience of a medicines reference-pricing model. S Afr Med J 2004;94(3):183-188.

20. Fairfield G, David JH, Mechanic D, RosleffF. Managed care: Implications of managed care for health systems, clinicians and patients. BMJ 1997;314(7098):1895. https:// doi.org/10.1136/bmj.314.7098.1895

21. Council for Medical Schemes. Consumer assistance. http://www.medicalschemes. com/Content.aspx?17 (accessed 4 November 2019).

22. Council for Medical schemes. Contribution and benefit changes. http://www. medicalschemes.com/files/Circulars/Circular_34_of_2006_Contribution_and_ Benefit_Changes.pdf (accessed 4 November 2019).

23. Healthcare and Lifescience Review. South Africa Pharma Report. HLR, 2016. https://pharmaboardroom.com/pharmareport/south-africa-pharma-report (accessed 10 March 2019).

24. Trap B, Hansen EH, Hogerzeil HV. Prescription habits of dispensing and nondispensing doctors in Zimbabwe. Health Pol Plan 2002;17(3):288-295. https:// doi.org/10.1093/heapol/17.3.288

25. African National Congress. Let's grow South Africa together. 2019 election manifesto: A people's plan for a better life for all. https://voteanc.org.za/assets/ manifesto-summaries/A5_Manifesto_English.pdf (accessed 4 November 2019). 